\title{
Niewinne czy obciążające rokowanie zmiany odcinka ST? Przypadek 54-letniego chorego po nagłym zatrzymaniu krążenia, bez zmian w naczyniach wieńcowych - zespół Haissaguerre’a
}

\section{ST segment's changes - harmless or malignant influence on the prognosis? Case report of 54-years-old patient after sudden cardiac arrest, without coronary artery lesion - Haissaguerre syndrome}

\author{
Marta Agnieszka Nowakowska, Karolina Frynas-Jończyk, \\ Małgorzata Kurpesa, Jarosław Damian Kasprzak \\ Klinika Kardiologii Uniwersytetu Medycznego w Łodzi
}

\section{Streszczenie}

Zespół Haissaguerre'a charakteryzuje się współwystępowaniem zmian elektrokardiograficznych, tj. uniesieniem punktu J o charakterze zazębienia lub zwolnionego obniżenia końcowego załamka R w odcinek ST o co najmniej 0,1 mV w przynajmniej dwóch sąsiadujących odprowadzeniach, niezależnie od obecności uniesienia odcinka ST, w odprowadzeniach znad ściany dolnej, tj. II, III, aVF bądź bocznej I, aVL, V4-V6 z nagłym zatrzymaniem krążenia. W trakcie diagnostyki różnicowej należy uwzględnić inne przyczyny uniesienia odcinka ST, to znaczy ostry zespół wieńcowy z uniesieniem odcinka ST - STEMI, zapalenie osierdzia, hiperwagotonię czy zespół Brugadów.

Słowa kluczowe: zmiany odcinka ST, zespół Haissaguerre’a

Folia Cardiologica 2017; 12, 3: 281-284

\section{Wstęp}

Zespół wczesnej repolaryzacji (ERS, early repolarization syndrome) początkowo definiowano jako wysokie odejście punktu J z towarzyszącym uniesieniem odcinka ST o 1-4 mm w stosunku do linii izoelektrycznej, uniesienie odcinka ST wklęsłe z symetrycznymi załamkami T. Długo traktowano ERS jako prawidłowy wariant zapisu elektrokardiograficznego (EKG), szczególnie często występujący u młodych, zdrowych mężczyzn, zwłaszcza rasy czarnej i u sportowców. W 2008 roku Haissaguerre i wsp. [1] zwrócili uwagę na odrębne znaczenie rozpoznania zespołu określa- nego jako uniesienia punktu J o charakterze zazębienia lub zwolnionego obniżenia końcowego załamka R w odcinek ST o co najmniej 0,1 mV w przynajmniej dwóch sąsiadujących odprowadzeniach, niezależnie od obecności uniesienia odcinka ST. Powyższe zmiany występowały w odprowadzeniach znad ściany dolnej, tj. II, III, aVF bądź bocznej I, aVL, V4-V6. W wieloośrodkowym badaniu obejmującym 206 chorych po przebytym idiopatycznym migotaniu komór stwierdzono częstsze (31\%) występowanie cechy ERS w EKG w zakresie ściany dolno-bocznej w porównaniu z ogólną populacją (6\%) [1]. Ze względu na znamiennie różne rokowanie ostatecznie postanowiono oddzielić pojęcia zespołu wczesnej 


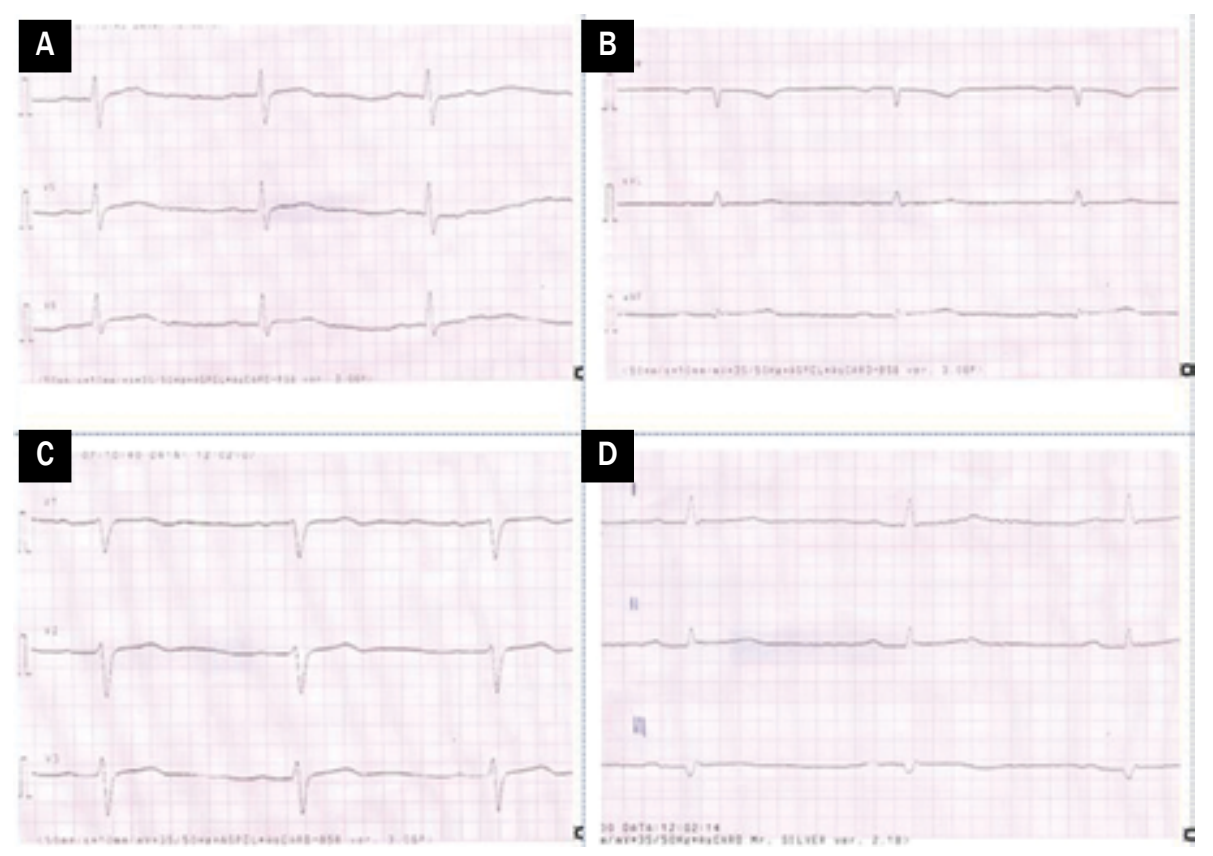

Rycina 1A-D. Zapis elektrokardiograficzny pacjenta przy przyjęciu do kliniki - po reanimacji prowadzonej przez zespół pogotowia ratunkowego, po kilkukrotnej defibrylacji miarowy: rytm zatokowy o częstotliwości 70/min, uniesienie odcinka ST w odprowadzeniach II, III i aVF (maksymalnie o 2 mm w II), z widoczną falą J w odprowadzeniach II, III i aVF, patologiczny załamek Q w odprowadzeniu III; PQ = 0,2; $\mathrm{QRS}=0,08 ; \mathrm{QTC}=380 \mathrm{~ms}$

repolaryzacji oraz zespołu Haissaguerre'a. Ten ostatni rozpoznaje się u chorych po przebytym migotaniu komór (bez przyczyny wtórnej) z falą J, uniesieniem punktu J o co najmniej $1 \mathrm{~mm}$ w odprowadzeniach II, III, aVF lub/i V5-V6.

\section{Opis przypadku}

Chory w wieku 54 lat, dotychczas nieleczący się, stracił przytomność w domu. W EKG stwierdzono migotanie komór; wykonano 6-krotną defibrylację. Ostatecznie po około 30 minutach reanimacji uzyskano powrót czynności hemodynamicznych.

W chwili przyjęcia chory był w ciężkim stanie z hipotonią (80/60 mm Hg), nieprzytomny, zaintubowany, wentylowany mechanicznie (4 pkt. w Glasgow Coma Scale). W wynikach badań laboratoryjnych stwierdzono prawidłowe stężenie elektrolitów oraz nieznacznie podwyższone wartości enzymów uszkodzenia mięśnia sercowego (troponina T [TnT, troponin $T$ 0,3 ng/ml). W EKG obserwowano miarowy rytm zatokowy o częstotliwości 70/min, uniesienie odcinka ST w odprowadzeniach II, III i aVF, maksymalnie o $2 \mathrm{~mm}$ w odprowadzeniu II, z widoczną falą J w odprowadzeniach II, III i aVF, patologiczny załamek Q w odprowadzeniu III (ryc. 1). $W$ badaniu echokardiograficznym stwierdzono rozległe odcinkowe zaburzenia kurczliwości, z frakcją wyrzutowa (EF, ejection fraction) $25 \%$. W wykonanej koronarografii nie wykazano zmian w naczyniach wieńcowych. W badaniu radiologicznym (RTG) klatki piersiowej i tomografii kompute- rowej (CT, computed tomography) głowy nie uwidoczniono odchyleń. Zastosowano farmakoterapię - wlew amin katecholowych oraz empiryczną antybiotykoterapię.

Po rozintubowaniu chory pozostawał w stanie średnio ciężkim, byłjednak wydolny krążeniowo i oddechowo. W EKG stwierdzono rytm zatokowy, utrzymywanie się uniesienia odcinka ST w odprowadzeniach II, III 5 aVF (maks. 2 mm w odprowadzeniu II), patologiczny załamek Q w odprowadzeniu III oraz ujemne załamki T w odprowadzeniu V1-V5. W kontrolnym badaniu echokardiograficznym zaobserwowano niewielkie odcinkowe zaburzenia kurczliwości - hipokinezję 1/2 podstawnej ściany bocznej z EF równą $56 \%$. Ze względu na przebyte nagłe zatrzymanie krążenia bez uchwytnej przyczyny podjęto decyzję o implantacji kardiowertera-defibrylatora w ramach prewencji wtórnej (ryc. 2).

Na podstawie całokształtu uzyskanych wyników badań, po wykluczeniu wtórnych przyczyn, za najbardziej prawdopodobną przyczynę nagłego zatrzymania krążenia uznano zespół Haisseguerre'a.

Po blisko 2-letniej obserwacji chory pozostaje w dobrym stanie ogólnym, bez nawrotów zagrażających życiu arytmii w trakcie kontroli kardiowertera-defibrylatora oraz w 24-godzinnym monitorowaniu EKG metodą Holtera (ryc. 3).

\section{Omówienie}

Uniesienie odcinka ST u chorego z nagłym zatrzymaniem krążenia rodzi w pierwszym rzędzie podejrzenie ostrego 
A

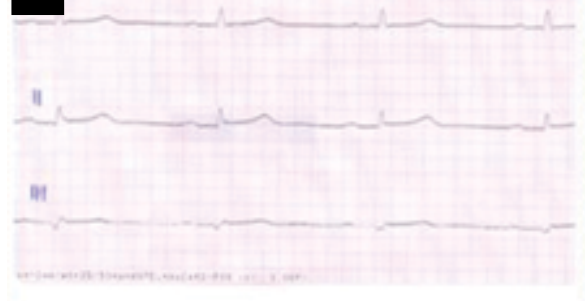

C

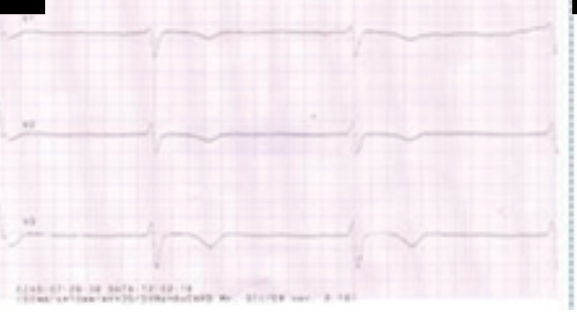

B

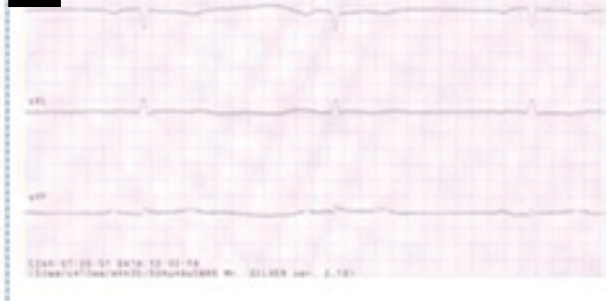

D

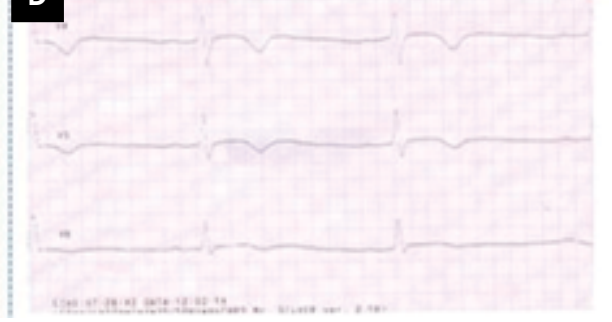

Rycina 2A-D. Zapis elektrokardiograficzny w dniu przeniesienia chorego z oddziału intensywnej terapii do kliniki kardiologii: rytm zatokowy, utrzymywanie się uniesienia odcinka ST w odprowadzeniach II, III i aVF (maks. 2 mm w odprowadzeniu II), patologiczny załamek Q w odprowadzeniu III, ujemne załamki T w odprowadzeniach V1-V5

\section{A}

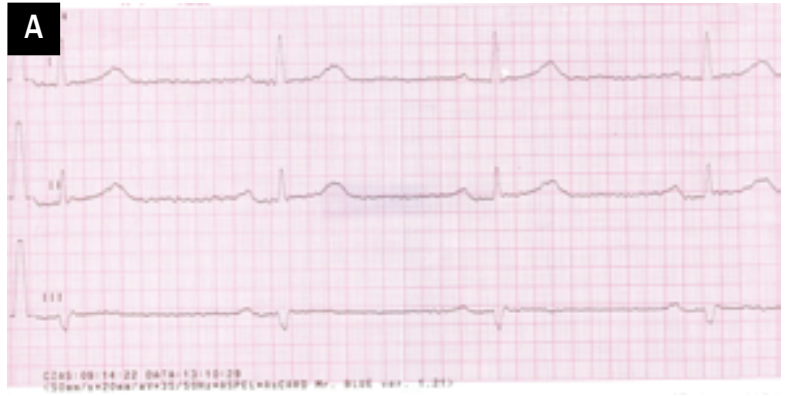

\section{C}

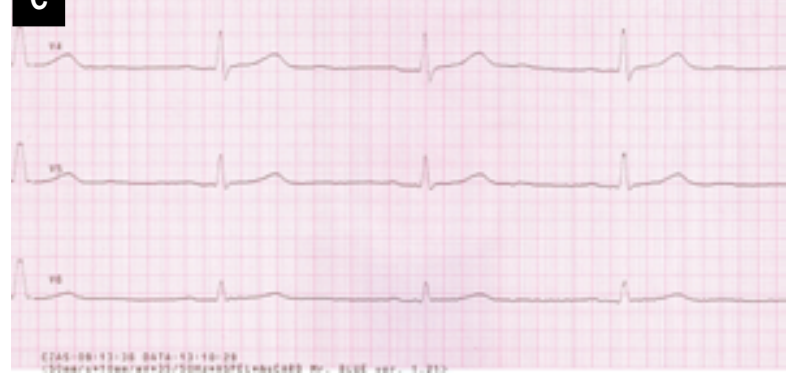

\section{B}

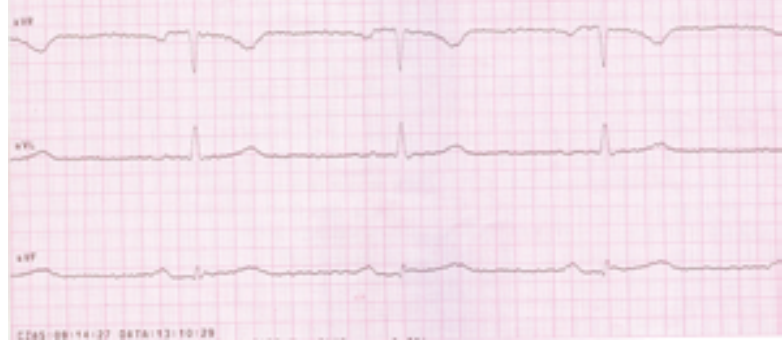

D

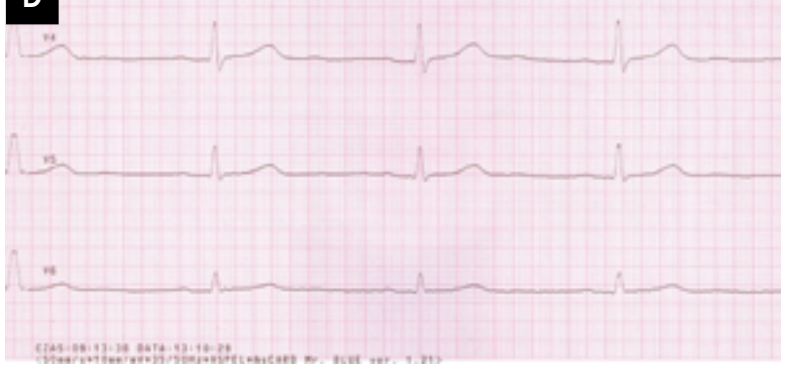

Rycina 3A-D. Kontrolne badanie elektrokardiograficzne po około 2 latach - miarowy rytm zatokowy o częstotliwości około 60/min

zespołu wieńcowego z uniesieniem odcinka ST. Charakterystyczne dla zawału serca zmiany to wypukłe uniesienie odcinka ST o typie fali Pardee'go z następowym pojawieniem się patologicznych załamków $Q$ oraz zmniejszeniem amplitudy załamków R. Wartości markerów uszkodzenia mięśnia sercowego były podwyższone u opisywanego pacjenta, jednak w koronarografii wykluczono chorobę wieńcową jako przyczynę zatrzymania krążenia. Kolejną jednostką chorobową, w przebiegu której można stwierdzić uniesienie odcinka ST, jest ostre zapalenie osierdzia. Wtedy najczęściej obserwuje się zmiany elektrokardiograficzne, takie jak poziome lub wklęsłe uniesienie odcinka ST w większości odprowadzeń, z towarzyszącym obniżeniem odcinka PQ, a także przeciwstawne obniżenie odcinka ST tylko w odprowadzeniach aVR i V1. Również u chorych z hiperwagotonią stwierdza się uniesienie odcinka ST, 
jednak - co istotne - o przebiegu skośnym ku górze ze współistniejącym zwolnieniem rytmu serca, wydłużeniem odstępów PQ raz zwiększeniem amplitudy załamków T.

Analizując grupę chorych po przebytym nagłym zatrzymaniu krążenia w mechanizmie migotania komór bez strukturalnej choroby serca w diagnostyce różnicowej, należy wziąć pod uwagę zespół długiego QT oraz zespół Brugadów. W spoczynkowym EKG nie ma nieprawidłowości w zakresie odstępu QT ani cech charakterystycznych dla rozpoznania zespołu Brugadów, tj. wysokiego odejścia punktu J przekraczającego $2 \mathrm{~mm}$ w odprowadzeniach przedsercowych V1-V3, z ujemnym załamkiem T w odprowadzeniach V2-V3.

Tikkanen i wsp. [2] zaobserwowali wzrost ryzyka zgonu sercowego w przypadku stwierdzenia w EKG uniesienia punktu J wynoszącego $1 \mathrm{~mm}$ lub więcej nad ścianą dolną oraz 3-krotny wzrost arytmii zakończonej zgonem w przypadku uniesienia punktu J o ponad $2 \mathrm{~mm}$ w tych samych odprowadzeniach. Prezentowane w literaturze opisy przypadków wskazują, że wyraźna fala J jest najlepiej widoczna bezpośrednio przed incydentem nagłego zatrzymania krążenia i po nim. Natomiast w późniejszym okresie pozostaje jedynie nieznaczne uniesienie odcinka ST w odprowadzeniach znad ściany dolnej [3, 4]. W analizo- wanym przypadku było podobnie. Uniesienie było wyraźniej widoczne w krótkim czasie od zatrzymania krążenia niż w odległej obserwacji. Ponadto na zapisie EKG ukazanym na rycinie 2 są widoczne ujemne załamki T, których nie było ani w pierwszym, ani w ostatnim zapisie EKG.

U opisywanego pacjenta występuje fala J, której towarzyszą horyzontalne uniesienia odcinka ST. W świetle ostatnich doniesień taki obraz EKG kilkunastokrotnie zwiększa ryzyko idiopatycznego migotania komór (IVF, idiopathic ventricular vibrillation) i jest znacznie bardziej obciążający rokowniczo niż uniesienia ST o przebiegu wstępującym nawet w przypadku obecności fali J [5].

\section{Podsumowanie}

Przedstawiony przypadek pacjenta, u którego rozpoznano zespół Haissaguerre’a, uzmysławia, z jaką starannością powinno się analizować zapis EKG, aby ułatwiał podejmowanie decyzji terapeutycznych, szczególnie w przypadkach stanów nagłych.

\section{Konflikt interesów}

Autorzy nie zgłaszają konfliktu interesów.

\section{Abstract}

Haissaguerre syndrome is an association between the sudden cardiac arrest and the $\mathrm{J}-$ point elevation with characteristic changes in the QRS complex - slurring or notching in the ECG leads II, III, aVF and/or I, aVL, V4-V6. During diagnostic we have to consider another causes of ST segment elevation for example ST segment elevation myocardial infarction, acute pericarditis, hypervagotonia, Brugada syndrome.

Key words: ST segment's changes, Haissaguerre syndrome

Folia Cardiologica 2017; 12, 3: 281-284

\section{Piśmiennictwo}

1. Mahida S, Derval N, Sacher F, et al. Sudden cardiac arrest associated with early repolarization. N Engl J Med. 2008; 358(19): 2016-2023, doi: 10.1056/NEJMoa071968, indexed in Pubmed: 18463377.

2. Tikkanen JT, Anttonen 0, Junttila MJ, et al. Long-term outcome associated with early repolarization on electrocardiography. N Engl J Med. 2009; 361(26): 2529-2537, doi: 10.1056/NEJMoa0907589, indexed in Pubmed: 19917913.

3. Shinohara T, Takahashi N, Saikawa T, et al. Characterization of $\mathrm{J}$ wave in a patient with idiopathic ventricular fibrillation. Heart Rhythm.
2006; 3(9): 1082-1084, doi: 10.1016/j.hrthm.2006.05.016, indexed in Pubmed: 16945806.

4. Jastrzębski M, Kukla P, Bacior B. [J-wave associated idiopathic ventricular fibrillation - a new arrhythmogenic syndrome?]. Kardiol Pol. 2008; 66(4): 447-449, indexed in Pubmed: 18473276.

5. Rosso R, Glikson E, Belhassen B, et al. Distinguishing "benign" from "malignant early repolarization": the value of the ST-segment morphology. Heart Rhythm. 2012; 9(2): 225-229, doi: 10.1016/j. hrthm.2011.09.012, indexed in Pubmed: 21914497. 